Hackler, C., Byse, E., Alves, T.C.L., and Reed, D. (2018). "Lean Leadership Training: Lessons from a Learner-Centered Analysis." In: Proc. 26 $6^{\text {th }}$ Annual Conference of the International. Group for Lean Construction (IGLC), González, V.A. (ed.), Chennai, India, pp. 484-494. DOI: doi.org/10.24928/2018/0522 Available at: www.iglc.net.

\title{
LEAN LEADERSHIP TRAINING: LESSONS FROM A LEARNER-CENTERED ANALYSIS
}

\author{
Cory Hackler ${ }^{1}$, Erika Byse ${ }^{2}$, Thais da C. L. Alves ${ }^{3}$, and Dean Reed ${ }^{4}$
}

\begin{abstract}
This paper presents an analysis of a Lean Leadership (LL) training program initiated by the company about two years ago. The program's main goal was to disseminate Lean throughout the company, which has been using Lean principles in its projects for about 20 years. So far, the LL program has reached over 280 participants. The program is constantly analysed via feedback provided by participants, however, no detailed analysis like the one presented herein has been conducted and shared. Participants of the program were requested to provide feedback about the program by answering a survey designed to capture their background and impressions the training.Data revealed that respondents with different roles, mostly related to field tasks, are attending the program and would recommend it to others. Most respondents consider themselves Lean leaders and educate others on Lean content. Respect for people, use of visuals, go and see, and use of PlanDo-Check-Act (PDCA) have been reported as Lean tools and principles constantly used. By sharing the lessons learned about this program, the authors expect to contribute to the change management and education literature within the Lean community.
\end{abstract}

\section{KEYWORDS}

Lean leadership, training, Lean journey, change.

\section{INTRODUCTION}

"A strong assumption within Toyota's culture is that managers are leaders and leaders are teachers" (Liker and Hoseus 2008, p.9). This statement summarizes the strong link between the culture at Toyota as an organization and how it views its leaders and managers as teachers who mentor their co-workers and share the company'scommon beliefs, values, and assumptions. Liker and Hoseus (2008) explain the cultural bond that links people at organizations using a Venn Diagram, which conveys the message that as individuals (depicted as circles) we have our own beliefs as well as beliefs that serve a common purpose in the organizations we work for. The overlapping areas between

\footnotetext{
DPR Construction, 1450 Veterans Boulevard, Redwood City, CA. CoryHa@dpr.com DPR Construction, 222 N. 44th Street, Phoenix, Arizona 85034, ErikaB@dpr.com Associate Professor, J.R. Filanc Construction Engineering and Management Program, Dept. of Civil, Constr., and Env. Engineering, San Diego State University, USA, talves@sdsu.edu

4 DPR Construction, 1450 Veterans Boulevard, Redwood City, CA. DeanR@dpr.com
} 
different circles in the Venn Diagram represent the common purpose people develop while working for an organization. The more people share in common, the more aligned they are expected to be in the pursuit of the company's goals.

This paper presents an analysisof a current effortby a construction company to align its personnel regarding the use of Lean through the development of a Lean Leadership training program. The program was first discussed in a previous IGLC paper (Hackler et al. 2017), which explained the initial steps the company took in their journey to develop Lean leaders. The current paper focuses mainly on some lessons learned from the program, what participants seem to value in the training program, what can be improved in the future. A brief literature review of previous efforts reported in the IGLC is presented, followed by the method to gather data and the presentation of results. The paper concludes with lessons learned from the program evaluation.

\section{LEAN PRICIPLES AND RELATED TRAINING}

The IGLC as a group has hosted over the years a track on "People, Culture, and Change" which presents studies on diverse topics related to Lean implementation and education, and its related challenges. Some of these papers have been broad in nature, and discussed attempts to train a company's personnel on Lean principles (Izquierdo et al. 2011) or train their extended supply chain of project participants on Lean Thinking (Napolitano and Cerveró-Romero 2012). Along these lines, Napolitano and Cerveró-Romero (2012) suggested a model to implement Lean across an organization and in its extended supply chain by involving 41 different companies to create what they called a meta-organization. Their main idea is to spread the knowledge of Lean to their partners so that everyone plays by the same rules and understands the necessary changes to be made to function as a Lean team.

Moreover, Mossman (2015) discussed a list of skills and knowledge required from those teaching Lean (e.g., leaders, coaches, consultants) and also highlighted the importance of having Lean training programs that are: multi-disciplinary, learnercentered, and with a focus on developing people and process skills. To support the teaching of Lean to industry practitioners, Rybkowski et al. (2011) developed a workshop to teach Lean concepts and Neeraj et al. (2016) organized a list of simulations to help practitioners get more engaged with the learning process, as suggested by Mossman (2015).

Other studies have focused on training to address specific issues related to Lean implementation. Leino and Elfving (2011) described a program to implement the Last Planner System and a zero accidents program, which involved educating and engaging the workforce, and the resulting improvements obtained in terms of health and safety including an $80 \%$ drop in the lost time accident rate in about 5 years.Aslesen and Tommelein (2016) suggested that last planners display different behavioral patterns that define how they plan and control their projects, and training should be provided to steer them to be more effective in the management of their projects.

The evaluation of the training program discussed in this paper addresses some of the issues identified in the literature. The training provided, as discussed by Hackler et al. 
(2017), provides participants coming from different backgrounds and with diverse types of responsibilities across the company the opportunity to engage in a Lean training. Participants are requested to read the course material for each module, and also to reflect how the material can be used in their projects and how they can effect change. The training is multi-disciplinary and learner-centered as suggested by Mossman, and addresses different concepts related to Lean. The following sections describe the method used to evaluate the program and to unearth some important perceptions and feedback from participants.

\section{RESEARCH METHOD}

The lessons learned reported in this paper are the result of a large training program under development at a company based in the Redwood City, California. The company founded in 1990 is a commercial contractor and construction manager, and has been ranked in the top 50 general contractors in the United States since 1997. It currently has 26 offices in the United States and three abroad.

The main tool used to develop the assessment of the LL program presented in this paper was an online survey deployed to current and former participants of the training. The authors brainstormed a set of questions that would capture some of the respondents' background as well as their feedback about the course modules and what they are doing with the knowledge they are gaining from the course. Finally, the survey tried to capture what can be improved in the program and how. The questions asked in the survey, which remained active for about two weeks, and the format of the answers were the following:

- Have you completed the Lean Leadership course? (Answers: Yes, I attended and completed the course; Yes, I am attending the course now;or Yes, I attended but have not yet completed the course)

- How long have you worked in the construction industry? $(0-5,5-10,10-15,15-20$, $20+) \mid$ How long have you been with DPR? (0-5, 5-10, 10-15, 15-20, 20+)

- Which of the following options best indicates the type of work you do for DPR? (Project executive, project manager, assistant project manager, superintendent, assistant superintendent, project engineering, estimator, scheduler, procurement, project pursuit/business development, design manager, other)

- Which were the most useful modules of the Lean Leadership training? Indicate your top 3. (Lean vs. Traditional; Principles \& Purpose; Focus/Alignment/Constancy, Student \& Teacher, Inquiry vs. Advocacy; Respect/No Blaming People, Value Stream Thinking, Effective Measurement, Reflection, Leader Standard Work, 'Go See' Leadership, Building Teams, Advocating Lean Thinking and Mitigating Resistance)

- Do you consider your project lean?(Yes/No) | Do you consider yourself a Lean Leader? (Yes/No) | How do you use the knowledge you gained from the Lean Leadership training in your daily routines? (Open question)

- Has the Lean Leadership program helped your team's performance? (Yes/No)| Briefly explain your answer to the previous question (Open question) 
- Do you recommend the Lean Leadership course to others? (Yes/No) | hy/Why Not?(Open question)

- What would you do to change the Lean Leadership course? (Open question)

- Do you educate others on Lean tools and processes? (Yes/No) | Briefly explain your answer to the previous question and describe any challenges you face when trying to educate others on Lean. (Open question)

Once the survey was closed, the authors divided the data mainly into demographics and the feedback or lessons learned obtained from the open-ended questions.

\section{SURVEY RESULTS}

\section{DEMOGRAPHICS}

A total of 85 respondents, out of 280 , who have participated in the Lean Leadership (LL) training answered the survey (30\% response rate). About $60 \%$ of respondents indicated that they had completed the course, and $39 \%$ were attending when data were collected for this paper, the remaining $6 \%$ have attended but not completed the course. There was a $50 / 50$ split in years of experience. The largest number of respondents (26\%) indicated that they have been with the company between 0 and 5 years, and $(26 \%)$ indicated they have been with the company $20+$ years, whereas $19 \%$ have been with the company between 5 and 10 years, and 21\% for 10-15 years, and finally (8\%) indicated $15-20$ years with the company.

When asked about how long they have worked in the construction industry, participants were fairly well represented in this survey, as shown in Figure 1. About $45 \%$ of respondents have been in the industry for up to 10 years, and the remaining $55 \%$ have worked for 10 or more years in the industry. About a quarter of them have worked in the industry for more than 20 years. These numbers indicate that while some of these respondents have been with the company for a short period of time, they have been in the industry for a much longer time and are willing to keep learning.

2. How long have you worked in the construction industry?
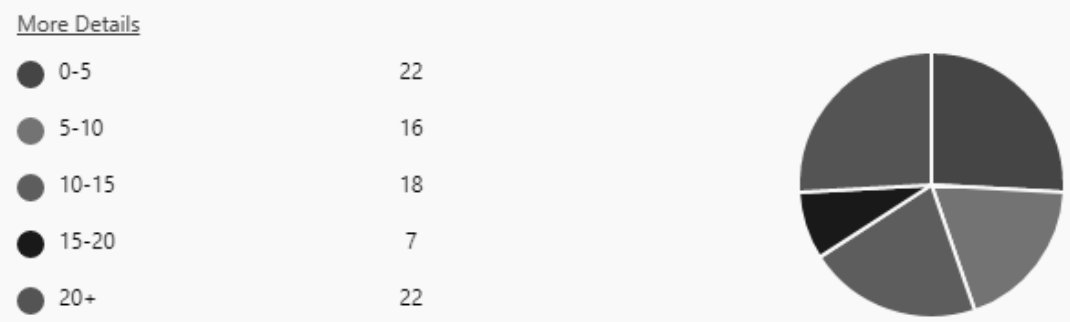

Figure 1: Time in the construction industry

Figure 2 reveals the main type of work respondents develop at the company. Interestingly, three of these categories stood out as they represent those who work close to the daily field operations necessary to deliver a project: superintendents $(24 \%)$ and project engineers $(24 \%)$, followed closely by project managers $(19 \%)$. This figure also 
illustrates the diversity of roles performed by the LL training participants providing a cross section of activities in the value chain of a project. However, the feedback is mostly provided by field-related personnel and not so much by office-related ones. No feedback was obtained from people who self-identify their work with areas such as procurement, design management, and project pursuit because these activities are handled by project teams and respondents did not view these roles as their primary work within the company.

4. Which of the following options best indicates the type of work you do for DPR?

\begin{tabular}{ll}
\hline More Details & 7 \\
\hline Project Executive & 15 \\
Project Manager & 1 \\
Sussistant Project Manager & 20 \\
Assistant Superintendent & 4 \\
Project Engineering & 20 \\
Schtimator & 5 \\
Procurement & 2 \\
Project Pursuit/Business Devel... & 0 \\
\hline Design Manager & 0 \\
\hline &
\end{tabular}

Figure 2: Type of work developed by respondents

Also, it is worth noting that the company has roughly one business development person per region (approximately 20 of them) and so far, only one has taken the course, whereas there are about 35 schedulers and 8 have taken the course. These collaborators might have taken courses and gone through training sessions elsewhere, but that was not captured in this survey.

\section{COURSE MODULES}

The LL training as deployed at the company is explained in more detail by Hackler et al. (2017) and based on the book by Gran et al. (2012). The training contains 13 modules, listed in Figure 3, and the top three modules as selected by the respondents included: Respect/No Blaming People, 'Go See' Leadership, and Lean vs. Traditional. It is worth noting that these results might be skewed because some of the respondents might not have yet covered some of the later modules shown in the sequence they are delivered in Figure 3. 
5. Which were the most useful modules of the Lean Leadership training? Indicate your top 3.

More Details

\begin{tabular}{ll} 
Lean vs Traditional & 30 \\
Principles \& Purpose & 25 \\
Focus/Alignment/Constancy & 22 \\
Student \& Teacher & 17 \\
Inquiry vs Advocacy & 17 \\
Respect/No Blaming People & 35 \\
Value Stream Thinking & 23 \\
Effective Measurement & 12 \\
Reflection & 15 \\
\hline Leader Standard Work & 13 \\
\hline Building Teams & 34 \\
\hline
\end{tabular}

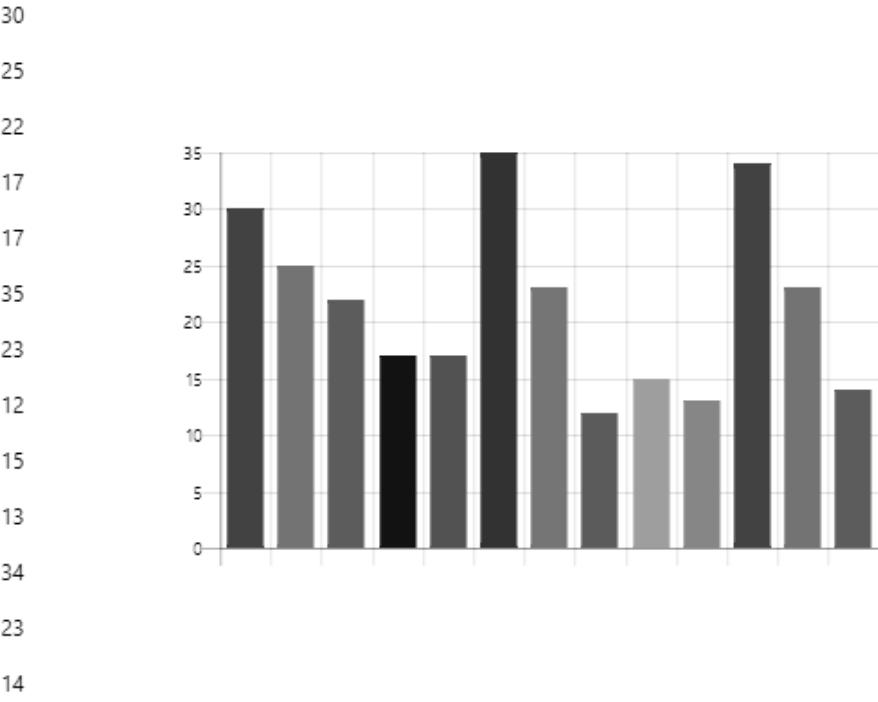

Figure 3: Preferred Lean Leadership course modules

\section{LEAN LEADERSHIP AND EDUCATION}

Respondents were asked in different questions to express their perceptions about how the program helped their teams and projects, whether they perceive themselves as Lean leaders and whether they are educating others on what they are learning in the LL course. Table 1 shows the responses indicating that $83 \%$ of respondents consider themselves Lean leaders and $85 \%$ educate others on Lean tools and processes. However, when asked if the LL program has helped their team's performance and whether they consider their projects Lean the numbers drop to $68 \%$ and $58 \%$.

Table 1: Lean leadership, Lean projects, and education

\begin{tabular}{lcc}
\hline \multicolumn{1}{c}{ Question } & Yes & No \\
\hline Do you consider yourself a Lean Leader? & $83 \%$ & $17 \%$ \\
Do you educate others on Lean tools and processes? & $85 \%$ & $15 \%$ \\
Has the Lean Leadership program helped your team's & $68 \%$ & $32 \%$ \\
performance? & & \\
Do you consider your project lean? & $58 \%$ & $42 \%$ \\
\hline
\end{tabular}

The results suggest that there is a gap to be bridged between translating the coursework to tangible actions to improve the projects, and there still much room for making projects Lean and improving their performance. The follow up questions to the ones presented in Table 1 provided some clues about the gap observed between being a Lean leader and being able to see results in their projects. 
When asked about how the knowledge gained from the Lean Leadership training was used in their daily routines, participants pointed to the: need to identify and eliminate waste; use of the Plan-Do-Check-Act (PDCA) cycle to identify problems and potential solutions (P), implement the solutions identified to solve the problems (D), check how the solutions are working (C) and act to correct deviations and promote continuous improvement (A); use of visuals to promote communication and more transparent environments, and respect for people. Selected quotes from participants include:

- I use inquiry much more and focus on process.

- I'm not sure I can say much of this was new to me personally. Rather, the training is giving me greater context to understand how we intend to incorporate these principles on our projects.

- Open Communication - Allowing open door policy where everyone feels safe to bring forward issues and feel they are heard when providing solutions. Recognizing potential problems before they arise and having options for solutions

- Greatly increased visual planning and communication of the plan. Daily huddles for accountability of the last 24 next 24. Use the ideas in the course to better explain my intent to the team.

- By consistently monitoring our project with the PDC[A] approach and encouraging feedback from our trade partners in eliminating waste and gaining value by striving for constant improvement.

- I've started to focus on the processes in place if something does not go as planned rather than critiquing the employee working on the task in hand. Making tasks more efficient leads to better results.

About two thirds of respondents (68\%) indicated that the LL program helped their teams performance, however, those who answered 'no' in general indicated the following reasons for their answer: they were early on the training, pushing for change is difficult, and their project team at large is not interested in Lean. Those who answered 'yes' largely pointed to issues related to: having more respect for people/partners, being able to better assess and solve issues, focusing on continuous improvement, raising awareness and alignment about Lean tools and principles helps the teams use them, using 'go and see' often. Some quotes from respondents include:

- Lean leadership promotes a more employee friendly environment and opens communication to improving what we do everyday.

- Its helped me ask more questions and drill down rather than immediately try to solve a teams problems.

- Strive to eliminate waste, get clarity in what is being requested. Value stream thinking (draining the river to see the underlying obstacles.

- Project Managers and Execs are using "go see" leadership much more often. 
Respondents overwhelmingly indicated that they educate others on Lean tools and processes $(85 \%)$, moreover, they indicated the challenges they face while trying to do so and what they have been doing to address that as part of a change process:

- I utilize what is learned in the class to improve jobsite efficiency and these tools and processes are shared with the project team. Challenges on educating others is when you are working with project team members that are very experienced in construction and not as easy willing to adjust to new practices.

- I try to educate my team on lean principles. Sometimes I get kickback because the principles are contrary to traditional thinking.

- Most are open minded but occasionally you encounter resistance. By showing success using lean techniques they learn that there are better ways of doing business.

- I don't phrase it as in "I am teaching you lean" but if there is an opportunity to improve something that I see, I will make the suggestion.

- I try to lead by example everyday. Our job as leaders of projects is not to make things harder, but to make work easier and more streamlined. We have to stop blaming the subcontractors for everything that goes wrong. We are the leaders!

Finally, almost $100 \%$ (only one respondent said 'no') of respondents indicated that they would recommend the LL program and offered feedback on what could be improved. Improving the videos, using examples from the construction industry and cases from the company's own experience, having face-to-face training and/or local community of practices, and discuss topics in a quick format or faster way were the most common types of comments.

\section{DISCUSSION AND MOVING FORWARD}

As results were being analysed, the first two authors who work as leaders of the LL training program defined the conditions of satisfaction $(\mathrm{CoS})$ for this program and divided them into personal $\mathrm{CoS}$ and Team $\mathrm{CoS}$ as shown in Table 2. 
Table 2: Conditions of Satisfaction for the LL Program

\begin{tabular}{lc}
\hline \multicolumn{1}{c}{ Personal level } & Team Level \\
\hline $\begin{array}{l}\text { Behavioral changes } \\
\text { Improved Quality of life (what's in it for } \\
\text { me) }\end{array}$ & $\begin{array}{c}\text { Consistency among projects } \\
\text { Teams are aligned around project } \\
\text { learning }\end{array}$ \\
$\begin{array}{l}\text { Engage in the material practice skill and } \\
\text { implement ideas of lean }\end{array}$ & $\begin{array}{c}\text { Empower LL to educate and change team } \\
\text { dynamics and inspire breakthrough } \\
\text { performance. }\end{array}$ \\
$\begin{array}{l}\text { Develop 1,000 LL in the company by the } \\
\text { end of 2019 }\end{array}$ & $\begin{array}{c}\text { Change perception that people are lean } \\
\text { but team are not. }\end{array}$ \\
Maintain 10\% drop our rate per class & $\begin{array}{c}\text { Lean champions on every team - project } \\
\text { and office. }\end{array}$ \\
Live in the PDCA cycle every day & \\
\hline
\end{tabular}

Based on the CoS presented and what the first two authors learned from the experience so far, some important changes are currently under way. While change in behavior is difficult to measure, the survey results show that over $80 \%$ of the students consider themselves Lean Leaders and educate others on Lean. However, the results also show that there is a $15-25 \%$ lower score on team performance. To drive the team performance higher, a pilot project cross-company team training was completed, and coaching is ongoing. Next, a newer company region will take the training together by having the initial kick-off, then a middle of the course check in, and a close out session all face-to-face. Additionally, to keep the effort "learner-centered", local Lean groups are starting up. One of the goals is to have a Lean champion on every team, project or office based.

To further describe some of the lean improvements that were made over the course of last year, here are the incremental changes:

- PDCA: The weekly check-in format was changed from asking each student to talk about their homework to 5 students talking about each of the homework questions. This greatly improved the discussion and allowed students to add specific points.

- 5S: OneNote for Meeting Notes was improved with better templates and real-time information from the Learning Center. This allowed the facilitators less time for setup and now 2 rounds occur in a 3-hour timeframe. This also allows makes it easier for new facilitators to see the process and focus on the people. Students now sign-up directly on the Learning Center.

- Transparency: A student scorecard in OneNote was used to show real-time weekly lesson progress, weekly check-in attendance and participation. This is driving our students to keep up with the weekly homework rather than complete it weeks after the check-ins complete. (Round 6 week 6 homework was at 25\% while Round 8 week 6 was $70 \%$ ). 
- Better Participation: The new question format, students keeping up with homework and tracking full participation has made for better weekly check-in conversations.

- Respect for People: Instructors and students started using their webcams so that the Go To Meeting become more personal. Coaching hours/student check-in have also been added.

- PDCA: The chat box was used for a plus delta and now added to the LL OneNote.

- Continuous Improvement: Learning Center reports were created so that the student's Apply Your Learning could be easily copied to OneNote reducing facilitator setup time.

\section{CONCLUSIONS}

The last year of LL has been a huge PDCA cycle for all of us involved in teaching Lean. We found that people have truly enjoyed the course by continuing to sign up and dedicate 9 weeks to the course on top of their daily responsibilities. They have walked away truly believing in PDCA, we had multiple students say that was their biggest takeaway from the last round of LL class. We have also known that LL participants are making big changes moving forward when using the PDCA cycle, they do not feel hesitant to stop, improve then move forward, typically right now people are scared to pause when they see issues with processes. Another big change is that managers are finding fault at processes and not people, knowing that processes will fail at some point. Teams are promoting a learning mentality when it comes to improving, causing teams to be open to continuous improvement.

Moving forward we are sticking to what has worked which is PDCA and asking the students (our customers) what they think will improve the course. For 2019, we will replace some of the content purchased from an outside vendor with our own employee's videos. We will choose one chapter and then ask our customers if they prefer our employee's examples or the examples given in the existing modules. If they like the changes, our plan will be to replace all content with internal examples. We will continue to drive toward a learning culture and want to see the numbers of people that say they are lean $(82 \%)$ to match the number of people that say their project are lean $(60 \%)$, if we are able to change this number then our workers are teaching and educating others and promoting the lean culture of learning.

\section{ACKNOWLEDGMENTS}

The authors would like to acknowledge the efforts of those who have participated in the training and helped redefine this journey. The views, comments, and opinions expressed in this paper are those of the authors and do not represent those of the company.

\section{REFERENCES}

Aslesen, S. and Tommelein, I.D. (2016). "What "makes" the Last Planner? A Typology of Behavioral Patterns of Last Planners.” Proc. 24th IGLC, Boston, USA, pp. 43-52 
Gran, S., Martichenko, R., Miller, and Pearce, R. (2012). People: A leader's day-to-day guide to building, managing, and sustaining lean organizations.LeanCor.

Hackler C., Byse E., Reed D., and Alves, T.C.L. (2017). "Building a Lean Culture" In:In: LC3 2017 Volume II - Proc. of the $25^{\text {th }} I G L C$, Heraklion, Greece, pp.309-316.

Izquierdo, J.L. , Cerf, M., and Gomez, S.A. (2011). "Lean Construction Education: Basic Management Functions Workshop." Proc.19th IGLC. Lima, Peru, 13-15.

Liker, J.K. and Hoseus, M. (2008). Toyota Culture McGraw-Hill: New York, NY. 562pp.

Mossman, A.(2015). "Bringing lean construction to life: Developing leaders, consultants, coaches, facilitators, trainers \& instructors."Proc. 23rd IGLC Perth. Australia, pp. 413-423.

Napolitano, P.D.T.S. \&Cerveró-Romero, F. 2012, 'Meta-Organization: the Future for the Lean Organization' Proc.20th IGLC. San Diego, USA, 18-20 Jul 2012.

Neeraj, A. , Rybkowski, Z.K. , Fernández-Solís, J.L. , Hill, R.C. , Tsao, C. , Seed, B., and Heinemeier, D. (2016). "Framework Linking Lean Simulations to Their Applications on Construction Projects."Proc. 24th IGLC. Boston, USA, 20-22 Jul 2016.

Rybkowski, Z.K. ,Munankami, M. , Gottipati, U. , Fernández-Solís, J., and Lavy, S. (2011). "Toward an Understanding of Cost and Aesthetics: Impact of Cost Contraints on Aesthetic Ranking Following Target Value Design Exercises", 19th IGLC. Lima, Peru. 